\title{
Transient Effects of Different Ventilation Methods on Car Indoor Air Quality
}

\author{
Feng-Chyi Duh \\ Correspondence: Feng-Chyi Duh,Ta Hwa University of Science and Technology, Taiwan \\ Received: May 19, 2015 Accepted: July 9, 2015 Online Published: July 15, 2015 \\ doi:10.11114/set.v2i1.891 URL: http://dx.doi.org/10.11114/set.v2i1.891
}

\begin{abstract}
This study investigated transient effects on the air quality of parked cars and moving cars with and without operating air conditioning. Carbon dioxide, carbon monoxide, volatile organic compounds, and formaldehyde concentrations were measured for comparative analysis. The results showed that simply changing the air conditioning system from internal circulation to external circulation to introduce air from outside reduces carbon dioxide concentrations by more than $50 \%$, volatile organic compound concentrations by more than $77 \%$, and the heat index from $0.1^{\circ} \mathrm{C} / \mathrm{min}$ to less than $0.05{ }^{\circ} \mathrm{C} / \mathrm{min}$. In order to conserve energy and improve car indoor air quality, this study can serve as a reference on healthy car environments.
\end{abstract}

Keywords: air quality, ventilation method, internal circulation, external circulation, heat index

\section{Introduction}

Vehicles are interior spaces with special environments. Most people in industrialized countries in Europe and the United States spend over one hour inside a vehicle every day (Müller, Klingelhöfer, Uibel, \& Groneberg, 2011). Americans spend a daily average of over 101 minutes inside vehicles, making it third most inhabited space next to homes and offices (Dong, Block, \& Mandel, 2004; Schlink, Thiem, Kohajda, Richter, \& Strebel, 2010). According to the white paper written by Taylor, Conor, and Lucas (2001), glass comprises only $12 \%-17 \%$ of the total square inch area of an average home; however it comprises $90 \%-100 \%$ of a car. This large area of glass results in extreme sun exposure which can lead to interior temperatures of up to $89^{\circ} \mathrm{C}$, whereas the dashboard temperature can reach up to $120^{\circ} \mathrm{C}$ (National Renewable Energy Laboratory, 2001).

The concentration of toxic compounds inside cars is easily influenced by the interior temperature. If the interior temperature in summer reaches $70^{\circ} \mathrm{C}$, the concentration of volatile organic compounds (VOCs) can increase by $40 \%$ (Geiss, Tirendi, Barrero, \& Kotzias, 2009). Results from similar research also show that in parked sedans, when interior ambient temperature is $26.7^{\circ} \mathrm{C}$, VOC values are approximately $400-800 \mu \mathrm{g} / \mathrm{m}^{3}$; when ambient temperature increases to $62.8^{\circ} \mathrm{C}$, VOC values increase five-fold. Research also shows that for moving vehicles with operating air conditioning, interior VOC concentrations are 4-8 times lower than for warm parked vehicles; VOC values were approximately $50-160 \mu \mathrm{g} / \mathrm{m}^{3}$. When the driver's side window was half opened, the VOC value decreased further (Fedoruk \& Kerger, 2003).

The interiors of new cars have been proven to contain 162 different VOCs, including formaldehyde and benzene; these VOCs are the cause of "new car smell" (Yoshida \& Matsunga, 2006; Janicka, Reksa, \& Sobianowska-Turek, 2010). The new car smell gradually dissipates as the car ages, but increases as the interior temperature rises. According to previous research, during the summers for the first three years after the car leaves the factory, VOC concentrations surpass 300 $\mu \mathrm{g} / \mathrm{m}^{3}$ (Maroni, 1995). The simplest method to effectively reduce the concentration of toxic compounds inside the car is to increase the air circulation speed. According to one study, an increase in air circulation speed from $0.1 \mathrm{~m} / \mathrm{s}$ to $0.7 \mathrm{~m} / \mathrm{s}$ reduced the concentration of VOCs in a car from $1780 \mu \mathrm{g} / \mathrm{m}^{3}$ to $1201 \mu \mathrm{g} / \mathrm{m}^{3}$ (You et al., 2007).

Gearhart and Posselt investigated two toxins, polybrominated diphenyl ether (PBDE) and phthalic acid ester (PAE), inside vehicles (Gearhart \& Posselt, 2006) and found that they are common inside cars and can pose a serious threat to drivers' and passengers' health. Zhang et al. (2008) observed 802 new cars parked in a well-ventilated underground parking lot and found that in $82 \%$ of the cars, toluene concentrations exceeded Chinese indoor air quality standards.

In sealed cars, the presence of a passenger creates harmful materials, for example, breathing increases levels of $\mathrm{CO}_{2}$ and humidity. As breathing converts $\mathrm{O}_{2}$ into $\mathrm{CO}_{2}$, the average adult exhales 100 times more $\mathrm{CO}_{2}$ than they breathe in 
(Čornak \& Braun, 2010). As a lack of oxygen slows brain reaction times and can cause dozing off, excessive $\mathrm{CO}_{2}$ concentrations may result in headaches and difficulty concentrating. According to reports from the American Society of Heating, Refrigerating and Air-conditioning Engineers (ASHRAE), average, healthy outdoor concentrations of $\mathrm{CO}_{2}$ are $350 \mathrm{ppm}$, and levels as high as approximately $500 \mathrm{ppm}$ are acceptable; at $800 \mathrm{ppm}$ air feels dirty and uncomfortable, and at 1,000 ppm people feel sleepy. Levels over 2,500 ppm are harmful to health, and levels over 3,000 ppm cause dizziness, headaches, and nausea. Another study indicated that over $90 \%$ of traffic accidents are caused by driver carelessness, and over $50 \%$ of traffic accidents are due to decreased driver concentration (Čornak \& Braun, 2010). As interior air quality has a direct influence on driver concentration, it has an indirect relationship with car safety.

Although many studies have applied various methods to improve interior air quality (Duh \& Lin, 2013; Zhang, He, \& Tanaka, 2006), using the car's air conditioning (A/C) system is the easiest method. However, turning on the A/C system can increase the car's energy consumption. For example, under normal conditions, the $\mathrm{A} / \mathrm{C}$ system in compact internal combustion engine vehicles consumes $5 \mathrm{~kW}, 10 \%$ of the car's total energy consumption. Turning on the $\mathrm{A} / \mathrm{C}$ while the car is moving causes gas performance to decrease (Yokoyama, 2011). While idling, the car's gas consumption increases by $14.2 \%$ (Shih, Liu, \& Liu, 2009). Therefore, adjusting the temperature and amount of wind inside a car according to the weather, especially in summer, and refraining from setting an extremely low temperature can help conserve energy.

The external circulation setting and fan ventilation on the $\mathrm{A} / \mathrm{C}$ system are two excellent methods to conserve energy and improve interior air quality. Our perceptions of hot and cold are not only determined by temperature, but are also influenced by humidity and wind speed. Different humidities and wind speeds at the same temperature result in different apparent temperatures. Most drivers are indifferent or oblivious to air currents or normally close the external circulation to prevent fumes or pollution from entering the car. This study aimed to investigate whether this method truly guarantees that interior air is not affected by outside pollution.

\section{Material and Methods}

The interior of a car is narrow and has poor ventilation. As there are many harmful gases inside cars, the cost of measuring the levels of a single compound is extremely high. Therefore, this study mainly measured total VOCs. Due to restricted use of the experiment equipment, this study focused on changes in the concentrations of four gases, namely, carbon dioxide $\left(\mathrm{CO}_{2}\right)$, carbon monoxide (CO), volatile organic compounds (VOCs), and formaldehyde (HCHO), in parked cars to propose a healthier car ventilation method.

This study used a 2005 Mitsubishi Savrin, a six-seat minivan with a $2000 \mathrm{cc}$ engine, average interior space of $3.4 \mathrm{~m}^{3}$, and an odometer reading of $145,000 \mathrm{~km}$. The car received regular maintenance and was in good operating condition. Car age has a specific influence on internal VOC concentration (Fedoruk \& Kerger, 2003). Normally, cars less than six months old are defined as "new cars" and those over four years old are defined as "old cars." There is a large disparity in VOC concentrations for new and old cars.

A multi-channel air quality monitor was used for sampling. This instrument is flexible and functional and can monitor multiple gases; its sampling component provides a stable flow and maintains a precise concentration. This study detected $\mathrm{CO}_{2}, \mathrm{CO}, \mathrm{HCHO}$, and VOC, gases listed by the Environmental Protection Administration, Taiwan (Taiwan EPA) and measured the temperature and humidity. The monitor is plug and play and shows detected levels in real-time. It has a universal serial bus (USB) transmission interface and can support datalog software for computer use. Considering restrictions due to power supply time and memory capacity, the sampling rate was set at once per second, i.e. $1 \mathrm{Herz}(\mathrm{Hz})$, and warm-up time was two minutes. A digital anemometer was used to detect the air velocity from the car vents; instrument precision was $\pm 2 \%$.

A parked car was defined in this study as a still car with its motor not engaged. Sampling began immediately after instruments were placed on the front passenger seat and the door was closed. A moving car was defined as a car with a person inside, the doors closed, and the engine running. Samples were taken for different ventilation methods (Table 1). Internal and external circulation for the moving car used the $\mathrm{A} / \mathrm{C}$ system to circulate the air inside the car. For both internal circulation and external circulation, when the $\mathrm{A} / \mathrm{C}$ fan was turned on, the air velocity from the central dashboard vent was $2.67-2.74 \mathrm{~m} / \mathrm{s}$ for the low setting and $2.86-2.87 \mathrm{~m} / \mathrm{s}$ for the high setting.

The first experimental data taken in this study was for a parked car in sunlight. The second to seventh experiments were for moving cars after sunset and before sunrise to prevent sunlight from influencing the temperatures. All experimental measurements were completed during the same week in the beginning of November; one experiment was completed each day. The outside ambient temperatures and ambient relative humidities are described in Table 1.

The human body lowers its temperature through sweating, during which the water in sweat evaporates, dispersing body heat. When relative humidity is high, the evaporation rate decreases. This indicates that the process of removing heat from the body also slows and the body retains more heat compared to when in drier air. Under known temperatures and humidities, a set of temperature and relative humidity can be converted into a higher temperature for dry air. This index 
that combines air temperature and relative humidity to confirm apparent temperature is normally referred to as the heat index $(\Psi)$ or equivalent temperature (Masterton, 1979) and is the perceived temperature. Using Celsius and relative humidity, the heat index formula is as follows:

$$
\Psi=T+\frac{5}{9}\left(P_{v}-10\right)
$$

where $T$ is air temperature in degrees Celsius and $P_{v}$ is vapor pressure. The formula for vapor pressure is as follows:

$$
P_{v}=6.122 \times 10^{7.5 T /(237+T)} \times \frac{\varphi}{100}
$$

where $\varphi$ is percent relative humidity and the heat index is based on a shaded area and not under direct sunlight. Generally, $\Psi>30^{\circ} \mathrm{C}$ may cause tiredness and discomfort. $\Psi>40^{\circ} \mathrm{C}$ may cause uncomfortable heat stroke, heat cramps, and heat exhaustion. $\Psi>45^{\circ} \mathrm{C}$ may cause dangerous heat stroke, heat cramps, and heat exhaustion. $\Psi>54^{\circ} \mathrm{C}$ may cause severe heat stroke.

Table 1. The experimental conditions

\begin{tabular}{ccccc}
\hline $\begin{array}{c}\text { Experimental } \\
\text { No }\end{array}$ & State & $\begin{array}{c}\text { Ventilation methods/ } \\
\text { Fan ventilation }\end{array}$ & $\begin{array}{c}\text { Environmental } \\
\text { temperature } \\
T\left({ }^{\circ} \mathrm{C}\right)\end{array}$ & $\begin{array}{c}\text { Environmental } \\
\text { humidity } \\
\Psi(\%)\end{array}$ \\
\hline$\# 1$ & Still car & SI / WO & 29.4 & 86 \\
$\# 2$ & Moving car & SI / WO & 26.1 & 86 \\
$\# 3$ & Moving car & IC / LS & 26.1 & 77 \\
$\# 4$ & Moving car & IC / HS & 25.6 & 80 \\
$\# 5$ & Moving car & EC / WO & 27.8 & 58 \\
$\# 6$ & Moving car & EC / LS & 26.2 & 56 \\
$\# 7$ & Moving car & EC / HS & 26.1 & 57 \\
\hline
\end{tabular}

SI: Sealed interior; WO: Without operating; IC: Internal circulation; EC: External circulation; LS: Low setting; HS: High setting

\section{Results and Discussion}

Figure 1 shows the changes in $\mathrm{CO}_{2}$ concentrations for each experiment. Data distribution indicates that $\mathrm{CO}_{2}$ concentrations for the parked car (\#1) remained at a stable average of $341 \mathrm{ppm} \pm 0.7 \%$ because the car was sealed and there were no passengers. This is slightly lower than the healthy outdoor standard (350 ppm) proposed by ASHRAE (ASHRAE Standard 62.1, 2004). For a moving car with a sealed interior (\#2), measurements show that $\mathrm{CO}_{2}$ concentrations reached $664 \mathrm{ppm}$ two minutes after the driver entered the vehicle; during the following two minutes of traveling at low speed, $\mathrm{CO}_{2}$ concentrations continued to rise by $12.6 \%$. When the car began to travel at high speeds, $\mathrm{CO}_{2}$ concentrations began to level off, then fall, and then continued to gradually rise. After the speed was reduced, $\mathrm{CO}_{2}$ concentrations in the car increased rapidly; at the end of the experiment, $\mathrm{CO}_{2}$ concentrations exceeded $1000 \mathrm{ppm}$. Continuing to look at Fig. 1, data distribution for the two internal circulation experiments for moving cars (\#3 and \#4) was similar to that for the sealed car (\#2); however, the amount of change decreased with the addition of introduced air. Experiment data for experiments \#2-\#4 shows that the final concentrations were 1.65, 1.25, and 1.10 times greater than the initial measurements, respectively.

For the external circulation experiments in Fig. 1 (\#5-\#7), initial conditions were similar to internal circulation (\#3 and \#4); however, after traveling speed increased, $\mathrm{CO}_{2}$ concentrations began to level off and fall, and were maintained as the car continued to drive. This trend was the opposite of experiments \#3 and \#4; therefore, the final concentrations were $0.67,0.85$, and 0.92 times lower than the initial measurements, respectively. Compared to experiments $\# 2---\# 4, \mathrm{CO}_{2}$ concentrations decreased by $60.9 \%, 53.3 \%$, and $50.6 \%$, respectively. From this we can see that changing the air conditioning system from internal circulation to external circulation to introduce outside air can reduce $\mathrm{CO}_{2}$ concentrations by over $50 \%$. 


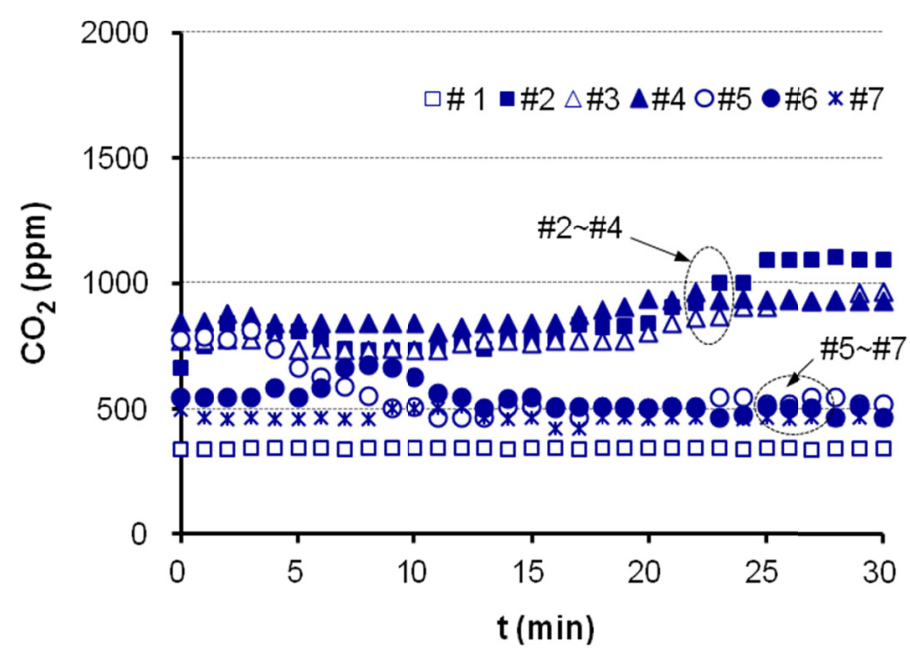

Figure 1. The changes in $\mathrm{CO}_{2}$ concentrations for each experiment

Generally, car exhaust does not contain excessive amounts of $\mathrm{CO}$, but the incomplete combustion that takes place when the engine idles releases large amounts of $\mathrm{CO}$. While driving, most people habitually turn on the $\mathrm{A} / \mathrm{C}$ system and close the windows to save energy as little outside air enters the car; therefore, there are no excessive levels of $\mathrm{CO}$ within the car. When the car in running, the air brought into the car through the $\mathrm{A} / \mathrm{C}$ system is fresh outside air. Therefore, when a car using the $\mathrm{A} / \mathrm{C}$ system stops, the intake vents take in exhaust from near the engine, and the interior begins to accumulate CO. Fig. 2 shows the changes in interior CO concentrations; data distribution does not show a regular and logical pattern between each experiment. CO concentrations were mainly influenced by the outside environment; for example, when driving on a heavily congested street, $\mathrm{CO}$ concentrations will increase, and when driving on a street with less traffic, $\mathrm{CO}$ concentrations will decrease. However, in all experiments, average $\mathrm{CO}$ concentrations inside the car were between $1.3 \mathrm{ppm}(\# 7)$ and $3.4 \mathrm{ppm}(\# 2)$, all lower than the permissible exposure limit (PEL) set by the US Environmental Protection Agency (US EPA) and ASHRAE (eight hour average $<9$ ppm) (Krarti \& Ayari, 2001).

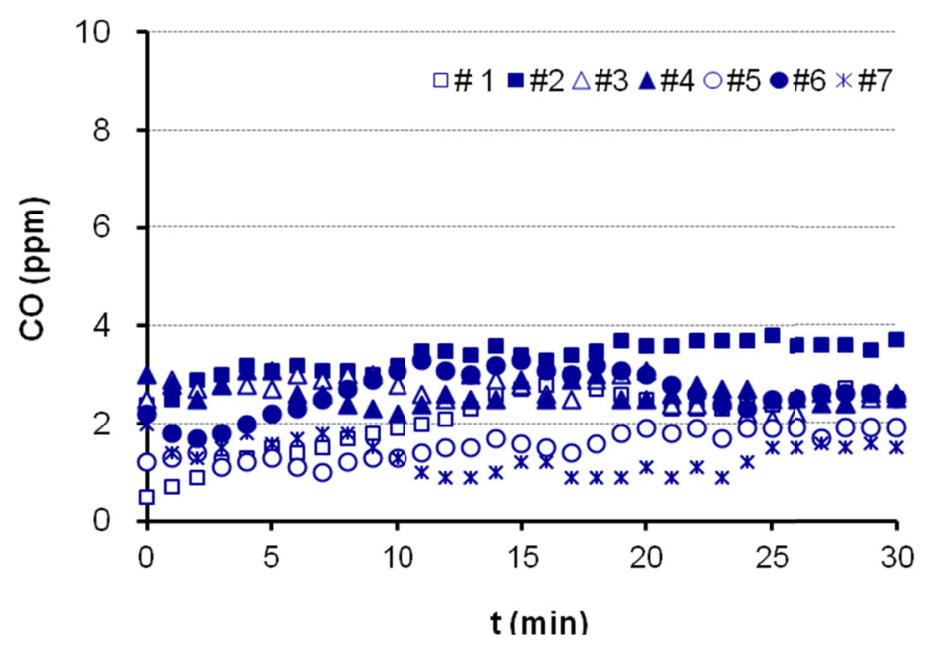

Figure 2. The changes in interior $\mathrm{CO}$ concentrations for each experiment

Among the substances most harmful to human health in an enclosed space are VOCs. VOC concentrations within a car are closely related to the car manufacturer, date of manufacture, and interior temperature. Fig. 3 shows the changes in interior VOC concentrations for each experiment. As the parked car (\#1) was under direct sunlight, internal temperatures were higher during the experiment $\left(35.3^{\circ} \mathrm{C}\right.$ average). Therefore, VOC concentrations maintained an average of $0.25 \mathrm{ppm}$. This is much lower than the PEL set by the Taiwan EPA (one hour average $<3 \mathrm{ppm}$ ). However, in the sealed cars with internal circulation experiments (\#2-\#4), VOC concentrations showed a gradual decrease; average concentrations dropped from $0.35 \mathrm{ppm}$ at the beginning to $0.11 \mathrm{ppm}$. As the car began to move, VOCs inside the car traveled outside through small cracks. In the external circulation experiments (\#5-\#7), the car interior had virtually no VOCs. This shows that external circulation has a significant effect on decreasing VOC concentrations. This is consistent with results found by You et al. (2007). 


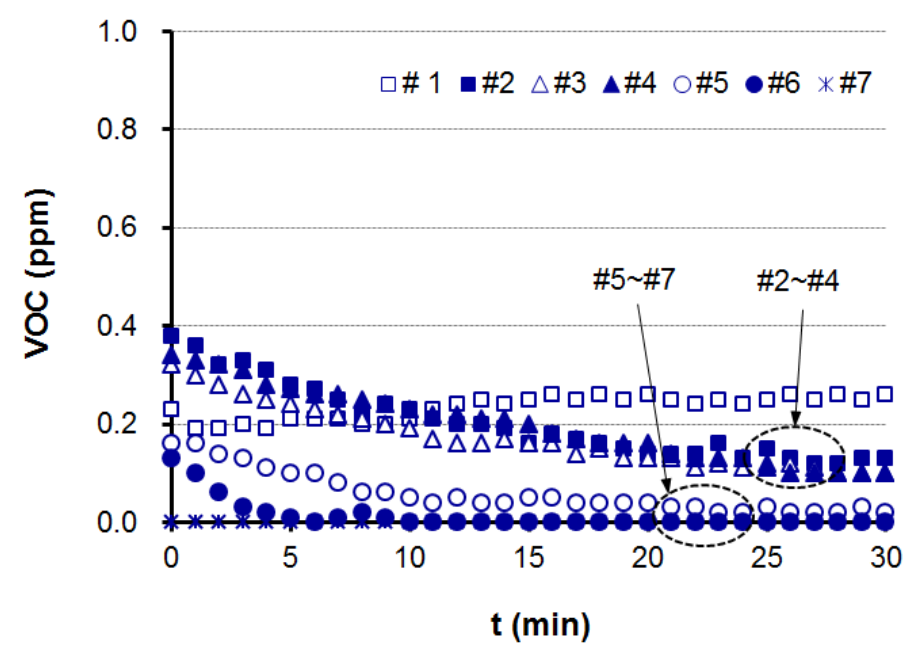

Figure 3. The changes in interior VOC concentrations for each experiment

Figure 4 shows the changes in interior $\mathrm{HCHO}$ concentrations. As the car was under direct sunlight for one day, despite it being nine years old, the data showed that a small amount of HCHO was still released. Data for the parked car (\#1) shows that $\mathrm{HCHO}$ concentrations stayed between 0.01 and $0.03 \mathrm{ppm}$. The average temperature during observation was $35^{\circ} \mathrm{C} \pm 6 \%$; these values are well below the PEL set by the Taiwan EPA (one hour average $<0.1 \mathrm{ppm}$ ) (Taiwan Environmental Law Library, 2005). For sealed moving cars with internal circulation (\#2-\#4), the average internal temperature during the experiments was $28.2^{\circ} \mathrm{C} \pm 1 \%$ and the $\mathrm{HCHO}$ concentrations averaged $0.17,0.12$, and $0.12 \mathrm{ppm}$, respectively. These values were slightly higher than the PEL set by the Taiwan EPA. For moving cars with external circulation (\#5-\#7), the average internal temperatures during the experiments were $27.2,26.8$, and $24.4^{\circ} \mathrm{C}$, respectively. Interior $\mathrm{HCHO}$ concentrations averaged $0.15,0.01$, and $0.01 \mathrm{ppm}$, respectively. Average $\mathrm{HCHO}$ concentrations dropped compared to experiments \#2-\#4. This indicates that without direct sunlight, using external circulation in moving vehicles can significantly reduce $\mathrm{HCHO}$ concentrations.

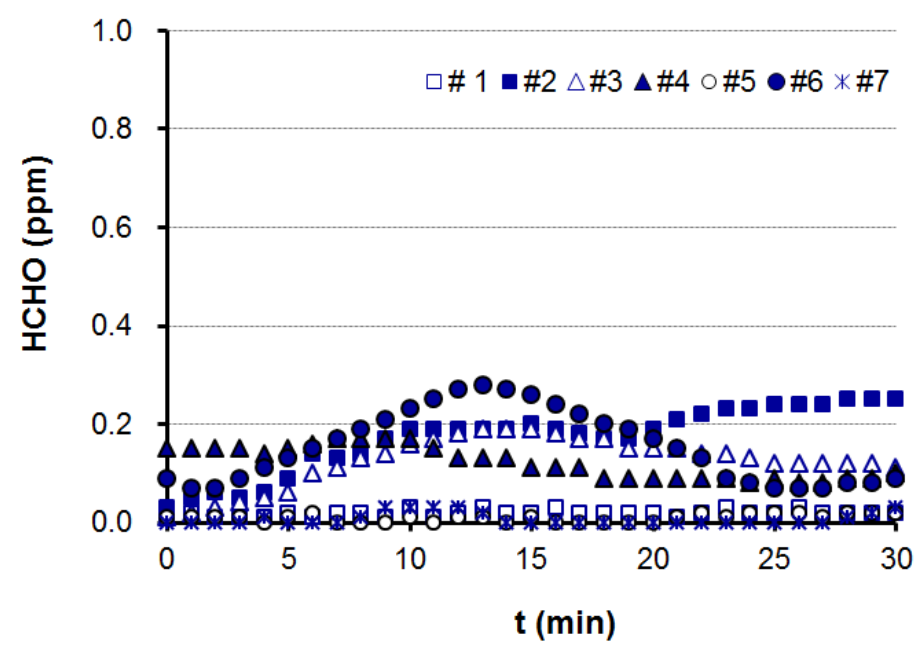

Figure 4. The changes in interior $\mathrm{HCHO}$ concentrations for each experiment

Eq. (1) and Eq. (2) can be used to calculate the heat index ( $\Psi)$ in order to describe the changes in $\Psi$ inside the car. The trends in Fig. 5 show that the $\Psi$ values for the parked car (\#1) gradually increased; the initial $43.4^{\circ} \mathrm{C}$ rose to $50.7^{\circ} \mathrm{C} \pm$ $0.4 \%$ after 17 minutes and remained steady. This indicates that at an outdoor temperature of $29.4^{\circ} \mathrm{C}$ and outdoor humidity of $86 \%$, the $\Psi$ values for a parked car changed from extremely uncomfortable $\left(\Psi>40^{\circ} \mathrm{C}\right)$ to dangerous $(\Psi>$ $45^{\circ} \mathrm{C}$ ). For sealed moving cars with internal circulation (\#2-\#4), $\Psi$ values all slowly increased at $0.1{ }^{\circ} \mathrm{C} / \mathrm{min}$, but remained below $40^{\circ} \mathrm{C}$ throughout the experiments. For external circulation (\#5-\#7), $\Psi$ values all rose at $0.05{ }^{\circ} \mathrm{C} / \mathrm{min}$, but remained below $35^{\circ} \mathrm{C}$. Interior $\Psi$ values also decreased as wind velocity from the A/C system increased. From this, we can conclude that using external circulation in moving cars can reduce $\Psi$ values to effectively increase comfort within vehicles. 


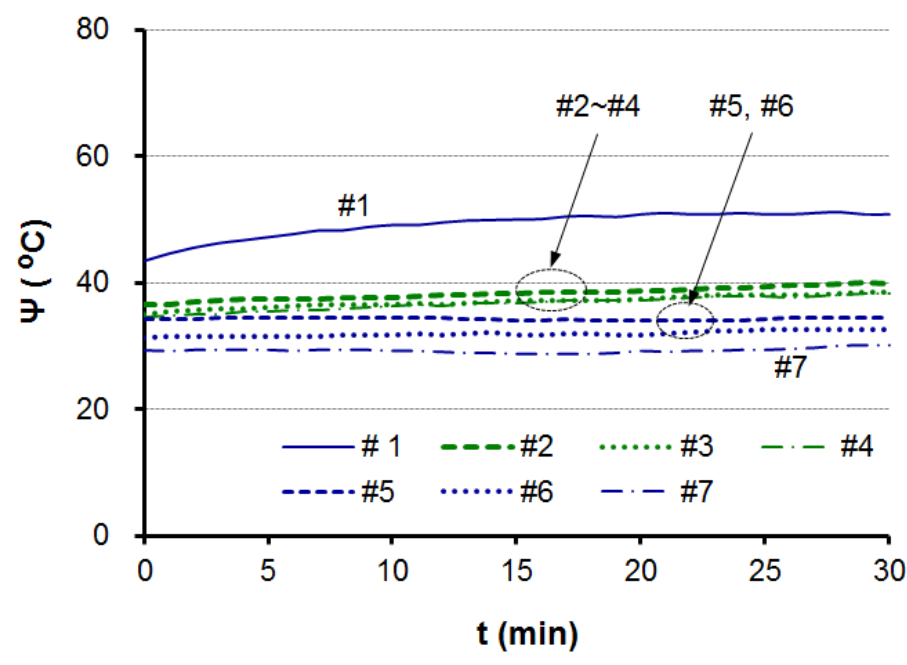

\section{Conclusions}

Figure 5. The changes in heat index $(\Psi)$ inside the car

Following the rapid, sustained growth of the automobile industry and vehicle consumption, air quality within cars has become an important social topic. Approximately $70 \%$ of drivers in Taiwan have never used external circulation; in other words, they have never introduced fresh outside air into their cars. Multiple harmful volatile organic compounds exist within car interiors, and in addition to the odors and viruses that accumulate with long-term use, the use of air fresheners merely masks smells perceived by passengers and does not remove odors, but further deteriorates air quality, adds to the burden on passenger health, and endangers safety.

Analysis results show that simply changing the air conditioning system from internal circulation to external circulation to introduce air from outside reduces carbon dioxide concentrations by more than $50 \%$, volatile organic compound concentrations by more than $77 \%$, and the heat index from $0.1{ }^{\circ} \mathrm{C} / \mathrm{min}$ to less than $0.05{ }^{\circ} \mathrm{C} / \mathrm{min}$. As such, these results could help remind drivers to utilize the $\mathrm{A} / \mathrm{C}$ system, and especially external circulation ventilation, while driving.

\section{Acknowledgements}

This work was financially supported by the Ministry of Science and Technology, Taiwan (grant no. NSC 101-2622-E-233-002-CC3).

\section{References}

ASHRAE Standard 62.1 (2004). Ventilation for acceptable indoor air quality. ASHRAE Inc., Atlanta, Georgia, USA

Čornak, Š., \& Braun, P. (2010). The evaluation of interior car's air quality and safety of traffic. Science \& Military, 1 , 36-39.

Dong, L., Block, G., \& Mandel, S. (2004). Activities contributing to total energy expenditure in the Unites States: Results from the NHAPS study. International Journal of Behavioral Nutrition and Physical Activity, 1(4). http://dx.doi.org/10.1186/1479-5868-1-4

Duh, F. C., \& Lin, S. M. (2013). Study on improving air quality inside parked vehicles. The Journal of Health Sciences 1(1), 1-15. (in Chinese)

Fedoruk, M., \& Kerger, B. D. (2003). Measurement of volatile organic compounds inside automobiles. Journal of Exposure Analysis and Environmental Epidemiology, 13(1), 31-41. http://dx.doi.org/10.1038/sj.jea. 7500250

Gearhart, J., \& Posselt, H. (2006). Toxic at any speed: Chemicals in cars and the need for safe alternatives. Michigan, MI: The Ecology Center.

Geiss, O., Tirendi, S., Barrero, J., \& Kotzias, D. (2009). Investigation of volatile organic compounds and phthalates present in the cabin air of used private cars. Environment International, 35(8), 1188-1195. http://dx.doi.org/doi:10.1016/j.envint.2009.07.016

Janicka, A. B., Reksa, M., \& Sobianowska-Turek, A. (2010). The impact of car vehicle class on volatile organic compounds_(VOC's) concentration in microatmosphere of car cabin. Journal of KONES Powertrain and Transport, 17(4), 207-212.

Krarti, M., \& Ayari, A. (2001). Ventilation for enclosed parking garages, ASHRAE Journal, 43(2), 52-55. 
Maroni, M., Seifert, B., \& Lindvall, T. (1995). Indoor air quality- A comprehensive reference book: Air quality monographs, 3, 819-821. Netherlands: Elsevier Science Publishers.

Masterton, J. M., \& Richardson, F. A. (1979). Humidex: A method of quantifying human discomfort due to excessive heat and humidity. Canada: Atmospheric Environment Service.

Müller, D., Klingelhöfer, D., Uibel, S., \& Groneberg, D. A. (2011). Car indoor air pollution- Analysis of potential sources. Journal of Occupational Medicine and Toxicology, 6(33). http://dx.doi.org/10.1186/1745-6673-6-33

National Renewable Energy Laboratory (2001). Development of a weather correction model for outdoor vehicle testing. Golden, Colorado, USA.

Schlink, U., Thiem, A., Kohajda, T., Richter, M., \& Strebel, K. (2010). Quantile regression of indoor air concentrations of volatile organic compounds(VOC). Science of The Total Environment, 408(18), 3840-3851. http://dx.doi.org/10.1016/j.scitotenv.2009.12.002

$\mathrm{Shih}_{2}$ Y. T., Liu, J. J., \& $\mathrm{Liu}_{2}$ H. F. (2009). The analysis of the power-assisted air-conditioning system in vehicle. Proceedings of the 4th Asian Conference on Refrigeration and Air-conditioning, Taipei, Taiwan.

Taiwan Environmental Law Library (2005). Recommended value for indoor air quality. Environmental Protection Administration, Taiwan. http://ivy5.epa.gov.tw/epalaw/ docfile/044310.pdf

Taylor, Z. T., Conor, C. C., \& Lucas, R. G. (2001). Eliminating window-area restrictions in the IECC. Washington: Pacific Northwest National Laboratory.

Yokoyama, A., Osaka, T., Imanishi, Y., \& Sekiya, S. (2011). Thermal management system for electric vehicles. SAE International Journal of Materials and Manufacturing, 4(1), 1277-1285. http://dx.doi.org/10.4271/ 2011-01-1336

Yoshida, T., \& Matsunga, I. (2006). A case study on identification of airborne organic compounds and time courses of their concentrations in the cabin of a new car for private use. Environment International, 32(1), 58-79. http://dx.doi.org/10.1016/j.envint.2006.08.007

You, K. W., Ge, Y. S., Hu, B., Ning, Z. W., Zhao, S. T., \& Zhang, Y. N. (2007). Measurement of in-vehicle volatile organic compounds under static conditions, Journal of Environmental Sciences, 19(10), 1208-1213. http://dx.doi.org/10.1016/S1001-0742(07)60197-1

Zhang, C., He, H., \& Tanaka, K. I. (2006). Catalytic performance and mechanism of a Pt/TiO2 catalyst for the oxidation of formaldehyde at room temperature. Applied Catalysis B: Environmental, 65, 37-43. http://dx.doi.org/10.1016/j.apcatb.2005.12.010

Zhang, G. S., Li, T. T, Luo, M., Liu, J. F., Liu, Z. R., \& Bai, Y. H. (2008). Air pollution in the microenvironment of parked new car. Building and Environment, 43(3), 315-319. http://dx.doi.org/10.1016/j.buildenv.2006. 03.019

\section{(cc) BY}

This work is licensed under a Creative Commons Attribution 3.0 License. 